\title{
Krize Müdahale ve Yas: Olgu Sunusu
}

\author{
O.E.Berksun*, A. Oral*, G.N. Ergin* , S. Azizoğlu*
}

Özet : Bu makalede yas reaksiyonu 5 vaka aracilı̆ı ile kriz yaktaşımı içinde ele alımmaktadir. Makale Krize Müdahale'nin Koruyucu Psikiyairi alanında uygulanabilir ve faydail bir yaklaşım olduğunu ve bu yaklaşımın kayıp sonrası kriz durumlarını çözümüne yardımcı olarak yas çalışmasını kolaylaştırdığını anlatmaktadır.

Summary: This paper describes the crisis approach to grief in five bereaved persons and illustrates the feasibility and usefulness of Crisis intervention in Preventive Psychiatry. The Crisis Intervention rapidly and efficiently facilitated grief work by resolving the crisis situation.

Tüm đünyada ve ülkemizde yaşanan olayların ve değişimlerinde katkısıyla, kitlesel ve toplumsal sorunların, bireylerin sorunlarının onüne geçtigi ve bireylerin yalnızlaştığı giünūmüzde, Koruyucu Ruh Sağıı̆ı çalışmaları daha da onemli hale gelmiştir. Bơyle bir dönemde A.U. Psikiyatrik Kriz Uygulama ve Araştırma Merkezi, ülkemizde, Konuyucu Psikiyatri alanında belirli bir kuramsal çerçeve içerisinde kurulan ve calış̧malarını sưrdüren ijk merkez ofma ozelliğini taşımaktadır.

Merkezimizde, günlük yaşam lçerisinde herhangi durumsal veya gelişimsel bir sorunjla başa çıkmada, güçluğ olan kişilere hizmet verilmektedir. Telefonta. başurular harţ̧ olmak üzere günde ortalama 6 , yılda ise 1500 danışma ve terapötik gōrüşme yapılmaktadır. Bu başvurularla sağlanan deneyim ve biriken veriler daha ileri ve kapsamí çalışmalara Işık tutucu niteliktedir. Ozellikle televizyon ve radyo programlarinda tanitimlardan hemen sonra Merkeze yapilan aralıksız telefon başvuruları, cok sayıda kişinin cesitti sorunlarla baş etmede güchữgü olduğunu ve bu tưrden hizmetlere ihtiyaç duyduğunu göstermektedir.

Krizler, tehlikeleri ve olumlu sonucları bir arada barındıran dönüm noktalarıdır ve genel anlamıyla dũzenli giden bir durumda meydana gelen bir bozulmaya işaret eder. Caplan ve Cullberg krizi, bireyin çeşitti durumlar veya yaşam olayları ile

A.Ü. Psikiyatrik Kriz Uygulama ve Araştıma Merkezi karşııştı̆ı̆ında bunlarla başedemeyecek şekilide ruhsal dengesinin sarsimasi hatta kaybı olarak tanımlamışlardir (Sonneck, 1985). Viney, krizde, gereken bilişsel bzümleme ve yeni başa çıma stratejilerinin geliştirlimesi ile birtikte diş kaynakların uygun kullanımı ve davranış değişikliklerinin gerçekleşemediğini belirtmiştir. Böyle noktalarda işlev gören, krize müdahale, bu yaktaşımın mimarı Caplan'a göre ikincil düzeyde (Secondary Prevention) ozzgül, koruyucu bir tedavi biçimidir (Staikeu, 1984).

Her insan kaçınımaz olarak, yaşamı boyunca, başetmesi gereken sayısız ołayla ve sorunla karşılaşır ve bu sorunlarin çoğunun üstesinden gelir. Ancak bu olayların bir kısmı, yaşamı, belirgin bir biçimde etkiler. Sevilen bir yakının beklenmedik ölumũ bu tip olaylardandır. Yaşamı çoğunlukla kesintive uğratır ve doğurduğu yalnızlık, ekonomik soruniar, bakım eksikliği, güvensizlik gibi ek stres kaynakları ite birlikte bireyi, biyopsikososyal alantarda çeşitli risklerle karşı karşıya bırakır. Yapılan araştımalar, yaşam olaylan sonrası rubsal ve bedensel hastalıkların insidansında bir artı̧ olduğunu góstermektedir (Parkes, 1964; Gelder ve ark., 1989; Barlow, 1988).

Günümüzde, sevilen bir yakının olümú nedeniyle ortaya çıkan, normal bir reaksiyon olarak değertendirilen yas reaksiyonu (DSM-|il-R, V62-82) üstüne pek çok yayın yapıımıştır. Freud'un 
"Mourning and Melancholia" (1917) adlı makalesinden sonra konuyu ilk kez kriz kuramı cercevesinde ele alan yazar E. Lindemann (1944) olmuştur. Yas, sevilen bir yakının ỏlümü ile ortaya çıan duygusal, bilişsel, davranışsal, bedensel ve sosyal alanlarda değişimlerle belirlenen karmaşık bir yaşantı, insan için kaçınılmaz ve evrensel bir deneyimdir. Bir yanıyla adaptif ve iyilessmeye hizmet eden (Olders, 1987; Schiff, 1986), ve bu nedenle bazı psikoterapi türterinde kullanlan (Pedder, 1982; Searles 1985; Volkan, 1992; Olders, 1987), diğer yanıyla Parkes'in (1965) söylediği gibi, enflamasyon reaksiyonlarına benzeyen ve çeşitli olumsuz gelişmeleri içinde barındıran bir sürreçtir.

Lindemann (1944) yası belirli semptomatolojisi ve gidişi olan bir sendrom olarak ele almıştır. Ona göre akut yas, ilk bakışta bir rahatsızłık olmasa da doğurabileceği sonuçlar açısından önemsenmesi ve ele alınmasi gereken bir durumdur. Bedensel ve ruhsal pek cok belirti ile seyredebilir, bir krizle ortaya çıkabilir, gecikebilir, abartılabilir, carpıtılabilir veya hiç ortaya çıkmayabilir. Böyle normal dışı seyir gösteren tablolar müdahaleyi gerektirir ve uygun teknikierle normal yas reaksiyonlarma çevrilebilir. Macnab (1989), yas reaksiyonu gösteren bireylerin acil olarak duygusal bir rehabilitasyon sürecine ihtiyaç gōsterdiklerini belirtir. Macnab'a göre bu sürecin önünde uç engel vardır. illki, bir yantsama olarak, ölenie iliş̧iyi sürdürmeye yarayan nevrotik duygusal acı çekme isteği, ikincisi, diğer insanların, geride kalanların sanki duygusal bir act içindeymiş gibi davranmalarına olan zorlayıcı beklentisi, ücünclusu ise yas içindeki insanların duygusal rehabilitasyonu bir amaç olarak görmemeleridir. Bu rehabilitasyon sürecinin önŭndeki engellerle birlikte, bireyin bułunduğu gelişimsel aşama, daha ónceki kayıplarla ilgili yaşanttlar ve bu kayıplarla başa çıkma biçimi, ólenle ilişkilerin boyutu vo niteliğj, özellikle ö̉ene karşı bilinç düzeyinde veya bilinç dışı ambivalansın veya düşmanlığın oluşu, işlevsel olan güncel sosyal destek sistemi, kişinin ölüme hazırlıkı olup olmadığ, kayıpla ortaya çıan ekonomik zorlukların boyutu, ritūelter aracılığıyla yas sürecini kolaylaşttran sosyokültürel yapı, kaybın ağırlığı ile birlikte içerdiği anlamlar ve doğurduğu sonuçlar yasın gidişini belirleyen önemlł faktörlerdendir (Binger ve Malinak, 1984). Çeşitil yazarlara göre terminoloji biraz farklı olsa da, genel olarak yas reaksiyonlari tipik yas ve patolojik (ya da komplikasyonlu) yas olmak üzere iki başlık halinde incelenir. Bibring ve Jacobson -Freud'un görūşlerı ile uyumlu olarak(1917)- patolojik yas reaksiyonlarının ortaya çıkmasında terkediımişlik yaşantısının rot oynadığı, kaybedilene duyulan öfkenin açığa vurulamaması, bastırılması ve özbenliğe yönettilmesinin önemine değinirler (Carr, 1985). Yas dönemindeki bir kişide ruhsal ve bedensel belirtiler lie birlikte bir depresif tablo söz konusudur. Ancak degersizlikk duygularının aşırı düzeye çıkması, iş yapma yeteneğinin uzun süreli ve ağır derecede azalması ve belirgin psikomotor yavaşlama, intihar dūşünceleri atışılagelmişin dışında belirtilerdir ve yasın major depresyon yönüne kaydığını gösterir. Yas tutan kişi kendi depresif duygulanımını normal bulur, ancak uykusuzluk, iştah kaybı deli olma korkusu ve bazı bedensel belirtiler nedeni ile hekime başvurabilir.

Merkezimize, sevilen bir yakının kaybı sonrası çeşiti yakınmalarla başuuran kişilerin sayıst ilk başvuruların \% 10'unu oluşturmaktadır. Deneyimlerimiz, 1-hastaların, Merkez' $\theta$, durumdan endişe duyan yakınlarının önerisi ve isteği doğrultusunda, 2-genellikje ölümden bir veya birkaç hafta geçtikten ve şok dỏnemi attatıldıktan sonra geldikeri ya da getirildiklerini, 3-ilk birkaç saat ya da gün içindeki, konversiyon, disosiasyon, kısa reaktif psikoz, kendini yaralama gibi nedenlerle yapilan başvuruların neredeyse tọmünŭn acil servise yapıldı̆ını, 4-Merkez'e yapılan başvurularda önde gelen nedenlerin yoğun sıkınt, depresif belirtiler, günlük işlerini sürdürmede zorlanma, isteksizlik, intihar düşünceleri veya girişimleri, unutkanłık, konsantrasyon güçlăgüu, uykusuzluk ve somatik yakınmalar olduğunu, 5-ölümō takip eden birkaç aydan sonraki başvuru nedenlerinin ise daha çok sosyal desteğin azalışının hissedildtği dönemde, örneğin, yalnızlık duygusu, dul kalma, sorumlulukların artması, ekonomik problemler, güvensizllk, başka ayrılık tehtioleri ve ne yapacağını bilememe ve uyum güçlükleri gibi ölümü izleyen sorunların yarattığı anksiyeteden kaynaklandığını góstermektedir.

Krize Múdahale'de temel ilke duruma olabildiğince çabuk mùdahale etmek ve kısa zamanda sonuca ulaşmaktır. Bu yaklaşım ıçinde tedavi ortalama 8 seansı kapsayan bir süreç içinde gerçekleştirilir ve eldeki tüm tedavi tekniklerinden yararlanisır. Krize Mõdahale'nin amacı -bir benzetme yapacak olursak- "nehirde bir yere taklip kalmıs bir kütūgưun yoluna devam etmesini sağlarnak" (Everstein, 1983) olarak açıkanabilir.

Her yaşam olayt gibj her kayı da bir krize neden olmamaktadır. Sleikeu (1984) ve Lundin, özellikle anl ve beklenmeyen ölümlerin ağır bir yas reaksiyonu ile birlikte bir kriz durumuna neden 
olduklarını belirtmektedirler. Aşağıda sunulan olguların biri hariç hepsinde kayba bağı̆ ăğı bir yas reaksiyonu ve kriz sőz konusudur. Bir kayıp sonrasında Krize Müdahale'nin amaçları soöyle özetlenebilir: Yas reaksiyonunun üstünü örttüğõ potansiyel kriz durumlarını saptamak, açık kriz durumarı için acil müdahalede bulunmak ve belirli bir kriz durumu olsun ya da oimasin yas sürecinin yolunda gitmesini sağlamaktır.

Aşağıda sunacağımız 5 trajikk olgu, kayıp gibi ağır bir yaşam olayının, biyopsikososyal alantarda, bireyleri pek çok riskle yüz yüze ve olumsuz gelişmelere karşı görece korunmasız bıraktığını göstermesi ve Krize Müdahale'nin önemini vurgulaması açısından önem taşımaktadır.

\section{OLGU SUNULARI}

1. OLGU: $Z, 42$ yaşında, evil, üniversite mezunu, 11 yaşında bir kızı olan, bir kamu kuruluşunda şef olarak çailşan , entellektüel düzeyi yüksek başarılı bir is kadını. Merkezimize, 22 yaşındaki üniversite son sınıf oggrencisi oğlunen bir trafik kazasında ölömünden üç hafta sonra yakınlarının önerisi ile başvurdu.

Ağır duygusal bir act içindeydi. Bu actya dayanamıyacağınt, ölen oğłunun kendisi için sadece bir evlat değıl yakın bir dost, herşeyini paylaştığı bir arkadaş ve küçăk kızı için de bir güvence olduğunu ve şimodi yaşamın bir anlamı kalmadığını sőylüyordu. Oğlunun blümánden hemen sonra ömeyi düşùnmüştŭ. Keder ve şiddetti sıkıntı hali ile bunlara eşlik eden isteksizlik, halsizlík, günlük aktivitelerini sürdürmede zorlanma ve özellikle allesi içinde duygularını paylaşmada, dışa vurmada güclük vardı. Ne yapacağını bilemez bir haldeydi. Oğlu ile yoğun bir biçimde uğraş halindeydi. îlk birkaç hafta yalnız başına amaçsızca dolaşı̆ğı zamanlar oimuştu. Oğlunun trafik kazası geçirdiğı caddeden işlek ołduğu zamanlarda bu olümôn nastl olduğunu anlamak için yavaş adımlarla geçme denemeleri yapıyordu. Z, kazadan Iki hafta kadar sonra bir kez ilaç içerek intihar etmek istemiş, son anda kızını düşünerek bunu yapmamıştı. Diğer insanlara karşı, görüşmelerde zorlukla dile gelen öłke ve düşmanlık ve bunlara eşlik eden suçluluk duyguları ve belirgin sosyal içe çekilme vardı. Gerçektik duygusunda da zaman zaman bozuimalardan, rüyalar ve benzeri yaşantılarla gelişen, oğlunun başka bir yerde enazından ruhunun yaşadığına dair gülü mistik, metafizik, parapsikolojik inançlarından bahsediyordu.
Terapistle ilişkilerinden ve hikayesinden olası obje ve sevgi kayiplarına óniem olarak insan iliş̧kilerinde temkinlì duygusal bir uzaklığı yeğlediğj, ancak zengin bir iç dúnyası olduğu, geçmişinde, yakın kişiler ve eşi ille llişkilerinde hayal kırıklıkiarı yaşadığı anlaşıliyordu. Görüşmelerde eşinden neredeyse hiç sőz etmemişti. 10 yll kadar öncesinde bir depresil atak hikayesi vardi. Kesitsel olarak bakıldığında parasuisidal, suisidal düşünce ve eylemlerin oluşu, bu hastanın derin bir yalnıziık duygusu, bir anlamda terkedilmişlik yaşadiğını vo bu hayatla iliş̧isinin kopmak ozere olduğunu gösteriyordu.

2. OLGU:K, 40 yaşinda alkol bağımılllı̆ı ve buna eşlik eden aniaşmazlıklar nedeniyle bir tartışma sırasında eşinin boşanma tehdidini cidolye alarak, eşiyle 3 ay kadar önce ani bir kararla boşanmı olan lise mezunu, bir karnu kuruluşunda memur olarak çalışan, yalnız yaşayan erkek hasta,

Merkezimize 12 yaşınđaki oğlunun ölümünden 2 gün sonra yakınlarının isteğı üzerine başvurdu. Ellerinde, kollarında, bacaklarında uyuşma, ağrı ve gücsuazlük gibj bedensel belirtilerden yakınıyordu. Oğlu iki gün önce kendisini iş yerinde görmeye gelirken bir trafik kazasında ölmüştă. Anamnestik bilgiden çocuğun, prematür denebilecek bir boşanma sonrasında, aktif bir rol üstlendiğf ve babayı hattada birkaç kez kendi isteği ile iş yerinde ziyaret ederek anne-baba arasındaki ilişkiyi ayakta tutmaya çalıştı̆̆ı anlaşilıyordu.

Birkaç hatta içinde yapllan ilk görüşmelerde K'da kendiliğindenlikte azalma, anksiyete hali dikkati çekiyordu; kayıpla ilişkili elem belirtileri açık değildi, hatta bu alanda duygusal bir yüzeysellik vardı. Her türlü ortamın kendisini bunalttığını söyıăyordu. Ozallikle somatik yakınmaları için bir ilą̧ önerilmesini istiyordu. Alkol kullanımında da bir artı̧̧ olduğu anlaşıtıyordu. Oğlunun öłümünden "çocuğun olümo" olarak belirli bir duygusal uzaklıkla bahsediyordu. Arada boşanma ile sonuçlanan bazi halledilmemiş sorunlar, büyük bir kayıpla yözleşmenin zorluğu ile birlikte yas sürecini yaşamayı engelifyordu. Yasın ertelenmesi, kaybın inkarı söz konusuydu. Ölüm öncesine ait "görülmemiş hesapları" vardı. Kazadan önce ve boşanma sonrasında ekonomik koşulları iyi olmadığı halde, isyerinden ücretsiz 6 ay izin alarak lsviçre'ye gitmek istemişti. Bu isteği kazadan dört hafta sonra da sürüyordu. İsviçre'de birkaç akrabanın dişında belirli ve sağlam bir bağı ve oradan bir beklentisi yoktu, amaçsızdi. 6 ay ucretsiz izinden sonra da belki de işini bıtakabileceğini 
sōylüyordu. Son dönemde alkol kullanımındaki artışla birlikte 1-bağımlıkı̆ın ağırlaşması, 2-psikolojik, sosyal: mesleki ve aileyi ilgilendiren alanlarda dürtüsel görünen, potansiyel ciddi tehlikeleri barındıran daha öncekj boşanma ve sonradan İsviçre'ye gitme kararı, 3-eski eşi ile ilişkilerinde kayıp sonrası belirgin yakınlaşma ile birlikte ne yapacağını bilemez bir durumda oluşu. 4-eski hesaplar in gündeme gelişi, 5-yasın en azından erteleniyor oluşu, bitişsel ve duygusal alanda bir karışıklığı ve dağılmayı gōsteriyordu. Daha çok, yoğunlaşan bağımlılık-bağımsızlık çatışması ve bu çałışmayla iłgili davranışarı ve eştik eden dürtüselliği nedeniyle pek çok riskle karşı karşıyaydı.

3. VE 4. OLGU: T, 39 yaşında, bił kamu kuruluşunda mimar olarak çalışan, entellektūel düzeyi yüksek 16 yılık evli bayan hasta. Merkezimize, 11 yaşındaki oğlunun tratik kazasında kaybından yaklaşık birbuçuk ay sonra bir arkadaşının önerisi üzerine başvurdu.

Ağır bir yas reaksiyonu gösteriyordu. Çevresine özellikle eşine karşı yoğun öfke ve düşmanlık duyguları ile baş etmede güçlūguo vardı. ilk görüşmeden sonra eşi ile birlikte görüşmeye alındılar. Eşi, N, 39 yaşında özel bir şirkette ûst düzey yöneticl konumundaydı; entellektüel dũzeyi yüksekti; 2 yı öncesine kadar bağımlılık düzeyinde alkol kullanımı oiduğgu ögrenildi. Aile öyküısunden son birbuçuk yıla kadar mutlu bir evlitikleri olmadığı anlaşııyordu. Birçok kez boşanma aşamasına gelmişler ancak vazgeçmişlerdi. $\mathrm{T}$, eşinin alkol sorunuyla birlikte kıskançıkları olduğunu, ỏzellikle evliliklerinin ilk yarısında bu yüzden ciddi zorluklar yaşadıklarını anlattı. Çocuklarının uzun bir tedavi sürecinden sonra olduğu, ve hastamızın eşine olan duygusal yatırımının bëyūk bir kısmını oğluna kaydırdığı, eşine küskün olduğu anlaşliyordu. Oğlu, büyüdükçe, $N$ ile arasında dengeleyiçi bir öge olmuştu. Zamanla T'nin küskünlüğö biraz. hafiflemişti. Son birbuçuk yildır mutluydutar ancak T'nin, N'nin alkole tekrar başlayacağı endişeși vardi. N kazanın öncesine rastlayan dönemde böbrek taş! nedeniyle gitmiş olduğu bir doktorun bira igmesini önermesi üzerine de günde birkaç bardak bira içmeye başlamıştı; akşam kazadan birkaç saat öncesinde de 3 bardak bira içmişti. Kaza yol yapımi nedeniyle yolun daraltıldığ bir bölgede arabanın devrilmesi şeklinde olmuştu. T'nin, bira öneren doktora ve eşi N'ye karşı büyük bir öfkesi vardı. Yas sürecini alabildiğine ağır yaşıyordu. N'ye karşı duygutarını kontrol altında tutmaya çalışıyor ancak bunu başaramadığı zamanlar oluyordu. Diğer zamanlarda duygularını açık açık yaşamakta pek zorłuğu olmuyordu. Yoğun öfkesi, yas sürecini etkiliyordu. Geçmişin hesapları bu gün hem kendi hem de eşinin durumunu zorlaştırıyordu. Birbilleriyle olabildiğince az konuşuyorlardi. $N$ suçluluk duygusu ile birlikte cezalandırılma, belirsiz de olsa hor görülme ve terkedilme yaşıyordu. Zaman zaman olửmũ düşünüyordu. Bentík saygısı düşūktü. Yas süreci ağır bir đepresyona kaymış görünüyordu. Seyrek de olsa alkol alımı süruyordu. İsinden ve bulunduğu şehirden ayrılıp bir kıyı kasabasıında bar açmak istiyordu. N'nin zor durumda ofuşu, uyandırdığı acıma duygusu ite T'nin korkutucu öfkesini bir ölçỉde dindiriyor ve dizginliyordu ama krize işaret eden bu denge eşin depresyonu ve aradaki iłişkimin riske edilmesi pahasına kuruimuş görünōyordu. Bugüne kadar kullanmış oldukları başa çıma yöntemleri đurumiarını zorlaştıłıyordu.

5. OLGU: J, 53 yaşında, evli, yüksek okul mezunu, 2 çocuklu bayan hasta. Ev eşyalartı satışı yaptığı küçük bir mağazası var. Merkezimize 23 yaşında üniversitede okuyan kızının trafik kazasında ölümünden yaklaşık 3 hafta sonra bir aile dostlarının önerisi üzerine başvurdu.

Kızı bir gece eve dönerken kendi kưlländığı otomobilin devrilmesi sonucu ölmūştü. Hastamı, kızını bağımsız, söz geçirilemeyen bir çocuk olarak tanımlıyordu. O gece de abisi lle eve dönebilecekken dönmemiş, birkaç saat sonra kendi otomobill ile gelmeyi yeğlemişti.

Tablo akut yas reaksiyonuydu ve hastanin anksiyetesi cok yüksekti, ancak bir depresyona eğilim farkediliyordu. Hastamız kızı ile, onun kişilik yapısından kaynaklanan çatışalar yaşadıklarından ve onunla pek yakın olamadıklarindan bahsedlyordu. Şimdi bu yakın olamayışdakj kendi payını sorguluyor ve kızını yalnız bıraktığını düşünüyordu. Terkedilme ve cezalandırımışlık duygusu ile birlikte kızının intihar etmeyi dūşünmüş olup olmadiğı bile aklına geliyordu. Kendisi de ölmeyi istiyordu. Günlük yaşamını sürdürmede zorlanıyordu. Belirgin bir duygusal dağınıklık içindeydi, balkondan gereksiz bir biçimde sarkma gibi parasuisidal eylemleri vardı. Her geçen günü kızına biraz daha yaklaşma olarak görüyordu.

Anamnestik bilgiden eşinin kendisinden 10 yaş būyük olduğu ögrenildi. Evlendiği günden beri eşinin baskın olduğunu ve kendi istediği gibi davranamadığın, hep ona uytum sağlamak ve 
isteklerine göre hareket etmek zorunda kaldığını; duygularını, istekjerini sürekli baskı altında tuttuğunu anlatt. Şimdi o yılları geri gettremeyeceğini söylüyordu. Genelde mulsuz bir evlilik tarifliyordu. 1 yl kadar önce de boşanma aşamasına kadar getinmiş ancak kızı buna engel olmuştu. J, kızı ile hemen hemen aynı yaşta iken evienmişti ve evilitik süresi lçinde kızı gibi bağımsız ve istediği gibi davranan biri ołmak istemiş ancak bunu başaramamıştı. Kızının ötomò aynı zamanda geçmiş yılların ve bentiğinin önemli bir parçasının kaybı olarak yaşanıyordu. Bu durum bir ceza olarak algilanıyor, kırgınlığa ve öfkeye sebep oluyordu. Duygularını ifade etmede aile içinde belirgin bir zorluk yaşıyordu. Suçlutuk duygusu tle bitikte benlik saygısinda ơnem!i bir dūşme vardi.

\section{OLGULARIN FORMÜLASYONU}

Yukarda sunulan olguların hepsinde denge durumunu bozan ağır bir kayıp, bu kayba eşlik eden kayıp tehditteri, belirgin bir zorlanma ve yardıma gereksinim söz konusudur. 5 olgunun ortak özellikleri: Aile bütünlügüüü bir biçimde koruyan ya da sağlamaya çalışan çocukdarın kaybedilmiş olışu; es ilişkilerinde güclükterin vartłgi ve ailenin kan-koca rollerinden cok ana-baba rolleri üzerinde yapilanma göstermesidir. Bu olgularda, kayıpla birlikte ana-baba rolünün sarsilması veya tamamiyle ortadan kalkması ve hastaların kendilerini artık bağları oimayan, bağımsız bireyler gibi görmeleri, $\Theta$ ve yakın çevreden uzaklaşmaya ve desteklerin yittrilmesine yol açmaktadır. Bu durum geçmiş yaşantıların ve sorunların da gündeme gelişiyle birlikte aile bütunlügŭnü tehdit etmekte ve ikinci bir kaybı gündeme getirmektedir. Bu açıklamadan da anlaşllacağı gibi 5 olguda da kaytp sonrasi dönemde geçrise ait pek çok tortu sorun, nhsal ve kişiler arası çatışmalar harekete geçmiş gözokmektedir. Hastalarda ağır bir yas reaksiyonu ile birlikte hem kaybın ve hem de kaybın doğurmuş olduğu sonuçarın üstesinden gelememe söz konusudur. Hastalar gocuklarının kaybı ile $\Theta \$ ̧$ ve aile kaybı tehdidi arasındaki bağı kuramamaktadırlar. Geçmiş̧ yaşantılara, hayatta olmaya ve kayba ait suçluluk duyguları ve buna bağlı reddedilme, terkedilme korkuları da eşler arasi ve aile içi duygusal iletişimi engellemektedir. Yas dönemine ait tüm duyguların ifadesi ve paylaşımında bir fakirlik dikkati cekmektedir. Olgulaiın hepsinde de yas komplikasyona uğramış görünmektedir.

\section{TEDAVI}

Yukarda sunulan 5 olgunun merkezimizde yapilan tedavileri daha önce söz edilen llke ve amaçar doğrultusunda gerçekieştirilmiştir. Terapötik yaklaşımda temel tedavi likeleri dogrultusunda, kabullenici, ilgili, sıcak bir tutum içinde olunmuş, tedavi ilişkisinin yeni ve sağlıkı duygusal bir iletişim ve obje itişkilerinin kurulmasında atılan bir adım olarak önemli oluşu hastalara hissettirilmiştir. Tüm gőrūsmelerde, bozulmuş ofan kendilik duyumu (Sense of Seli) ve hastalarm kendilerine güvenlerinin yeniden sağlanmasına dönök olunmaya özen gösterilmiştir. lik görōşmeden itibaren kazayla, ölenle ve kayıp sonrası yaşananlarla ilgili duyguların ifade edilebilmesine ve ayrıştırılabilmesine önem verilmiş ve hastalar bu yolda teşvik edilmiştir. Suçuluk, utanma, korku, ofke ve düşmanlık duygularını ayrıntılı bir biçimde konuşulmasına ağırlık verilmiş ozzeltikle eşlerte bu duyguların paylaşımı destekenmiştir. lik planda, bu yolla yas surecinl daha sağlıkl hale getirmeye katkıda bulunurken, süreç içinde ölen çocukların aile bütünlüğünü sağlayan rolleri üstlenilerek formülasyonda daha önce sözö edilen, aile lile ilgili sorun ve çatışma alanları üzerinde de duruimuştur. Kaypla birlikte krizi yaratan bu soruniar ele alınarak yasın işleyişini kolaylaştırmak amaçlanmıştır. Ortalama 7 'ser seans halinde yaptlan bu bireysel görüşmelerin ardından hastalar 13 seans süren bir grup tedavisine alınmıştır. Grup oturumlarında yas ve eşlerle ilgıı sorunfar üzerinde çalışımıştır. Tedavinin ileri aşamalarında eşlerin birbirlerine desteğ|nin büyük ölçüde artı̆ğı, eşlerden ve aile içi yaşantılarından sõz edilmeye başlandığı gözlenmiştir. Hastalar güniük yaşam içorisinde yasin yaşanmasına izin veriłmesi ve yasa zaman ayrıması gerektiğini farketmişlerdir. Suçuluk, utanma, korku, öfke, düşmanlık ve kırłlganfık gibi duygular çok daha kolay konuşulur hale gelmiştir. Tüm hastalar coçukların kaybı ile, ortaya çıkan tehditler arasındaki bağı anlamıs ve destek mekanizmasının işleyişini zorlaştıran tutumları konusunda en azından entellektüel düzeyde bir ı̧̣örö kazanmayı başarmışlardır. Sonţ̧̧ta bu tehditlere karşı yeni başa cıkma yöntemleri kullanmaya başlamışlardır. Hastaların işlev duzeylerinde de bir antı̧̧ olmuştur. J, eski işine donmüş̧ ve eşiyle bugüne kadar bulamadiğı sıcaklığı ve hoşgörüyō yaşadığını ifade etmiştir. $Z$ ve $T$ yaşantıları içinde cocuklarını eşlerinin yerine koymuş olduklarını farketmişlerdir. $Z$. kendine yeni uğraş alanları yaratmış, kayıp oncesinde alkol sorunu olan $\mathrm{K}$ kicin bir alkol servisinde tedavi organize 
edilmiş ve hasta alkof tedavisine girmiştir. Tedaviden 2 ay kadar sonra bu hastanın eski eşi ile yeniden evlenme planları içinde olduğu ŏgrenilmiştir. T'de ağır yas tablosu yatışmış görünmektedir. Ancak N'nin ağır sucluluk duygusu ve depresif belirtileri nin bir miktar da olsa yatışması $\mathbf{8}$ ay kadar bir süre almıştır.

\section{SONUÇ}

Toplumumuzda yalnızłığı ve yardımsız|ı̆ı yaşayan insanların sayısı tahmin edilenin ötesinde oldukça bayuak boyutlardadir. Insanın yalnızlık ve yardımsızlık duygusunu pekiştiren pek çok faktörün devreye girdiği günümüzde koruyucu psikiyatri alanında krize müdahale gibi yaklaşımların önemi artmaktadır. Bu makale ile, 5 olgudan yola çıkarak genellemelere varmak doğru olmasa da insanların yas reaksiyoniarı gibi alışıldık ve'normal kabuł edilen pek çok olay ve durum içerisinde iken yardıma intiyaçları olabileceğine vurgu yapmak istedik.

Yas insan için kaçınımaz ve her ne kadar normal bir yaşantı olsa da izlenmesi gereken bir durumdur. Ozeliikle bu alışıldık reaksiyonun krize donu̇şmüş olduğu kişilerde yakłaşım biçimi ne otursa olsun acil müdahaleye gereksinim vardır. Krize müdahale yaşam olayları sonrasında ortaya çıkan bu gibi durumlarda ilkeler açısından oldukça iş̧ yarar bir yaklaşım modelidir.

\section{KAYNAKLAR}

Bartow D.H. (1988) Models of Panic Disorder and a View from Emotion Theory. Review of Psychiatry, Frances A.J., Hales R.E. (Eds). Vol 7, American Psychiatric Press, Washington, DC.

Binger C.M.- Malinak D.P. (1984) Death and Bereavement. Review of General Psychiatry. Goldman H.H. (Ed). Lange Medical Publications, California.

Carr A.C. (1985) Grief, Mourning and Bereavement. Comprehensive Textbook of Psychiatry/IV. Kaplan H. I. , Sadock B.J.(Eds). Vol 2, Chapter 27.3:1286-1293. Williams and Jilkins, Battimore.

Everstine D.S.; EverstineL. (1983) People in Crisis, Bunner-Mazel Comp., Now York.

Froud S. (1917) Mourning and Melancholia. Standard edition, Volume 14, Hogarth Press, London.
Gelder M.; Gath D.; Mayou R. (1989) Oxford Textbook of Psychiatry. University Press, London.

Lindemann E. (1944) Symptomatology and Management of Acute Grief. Am J. Psychiatry 101:141-148.

Lundin T. (1984) Long-term outcome of Bereavement. British J. Psychiatry 145:424-428.

Macnab F. (1989) Life after Loss. Millenium Books, Philadelphia.

Olders H. (1989) Mourning and Grief as Healing Process in Psychotherapy. Can. J. Psychiatry 34 (4):271-278.

Parkes M.C. (1964) Recent Bereavement as a Cause of Mental ithess. Br.J Psych 110:198-204.

Parkes M.C. (1965) Bereavement and Mental IIness: A Classification of Bereavement Reactions. British J. Med. Psychol. 38:1-26

Pedder J.R. (1982) Failure to Mourn, and Molancholia. British J Psych 141:329-337.

Searles H.F. (1985) Separation and Loss in Psychoanalytic Therapy with Borderline Patients: Further remarks. Am J Psychoanal 45(1):9-34.

Schiff H.S. (1986) Living Through Mourning. Viking Penguin inc., New York.t

Slaikeu K.A. (1983) Crisis Intervention. Allyn añd Bacon, Inc., Boston.

Sonneck, G. (1985) Krisenintervention und Suisidverdhutung. Facultasverlag. Wien.

Volkan V.D. (1992) Psikanaliz Yaziları.(çvv. A.Cevik, B.Ceyhun) Hekimler Yaym Binliğ, Ankara. 